\title{
EFFECT OF MASSED PRACTICE VERSUS DISTRIBUTED PRACTICE ON BASIC MOBILITY SKILLS AMONG POST STROKE PATIENTS
}

\section{Parthiban Alagappan.}

Senior Physiotherapist (Grade - II), Department of Physical Medicine \& Rehabilitation, PSG IMS\&R Hospitals, Coimbatore, Tamil Nadu, India.

\section{ABSTRACT}

Background: Stroke a global health problem is the second commonest cause of death and fourth leading cause of disability. Bed mobility the most important requisite for all activities in impaired in stroke. Retraining of bed mobility skills is very important to gain better outcome in the later phases of rehabilitation. Based on the concepts of motor learning there are numerous practice methods to retrain motor skills. Since sufficient literatures are not available in comparing the effect of massed practice and distributed practice on bed mobility skills among post stroke patients, there is a need for incorporating it in this study.

Objectives: To compare the effect of massed practice and distributed on basic mobility skills among post stroke patients.

Materials and Methods: Study was conducted as a quasi experimental design - pretest and posttest designs with two comparison treatments at the Department of Physical Medicine and Rehabilitation ,KMCH Hospitals, Coimbatore, Tamil Nadu, India. A total of 20 stroke patients in the age group of 45 to 60 years participated in the study. The participants who satisfied the selection criteria were selected by convenience sampling and randomly assigned into two groups. Group A received bed mobility training using massed practice method and group B received bed mobility training using distributed practice method for 7 days. Outcomes were measured with bed mobility item of Stroke Rehabilitation Assessment of Movement (STREAM) scale.

Results: All participants in group A and group B showed significant improvement in bed mobility item of STREAM scale with a mean difference of 11.2 and 15.9 respectively. The calculated ' $t$ ' value using the paired test for group $A$ and $B$ were 27.03 and $51.36(P<0.005)$ respectively. When comparing between the groups using independent ' $t$ ' test, the bed mobility item of STREAM scores showed mean difference of 4.9 and ' $t$ ' value of $9.7(P<0.005)$.

Conclusion: This study revealed that there was significant improvement in bed mobility skills following distributed practice method than massed practice method among post stroke patients.

KEY WORDS: Massed practice, distributed practice, STREAM - Stroke Rehabilitation Assessment of Movement.

Address for correspondence: Parthiban Alagappan, Senior Physiotherapist (Grade -II), Department of Physical Medicine and Rehabilitation, PSG IMS\&R Hospitals, Coimbatore - 641004, Tamil Nadu, India.E-Mail: parthimpt13@gmail.com

\section{Quick Response code}

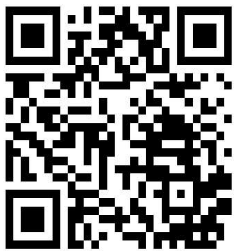

DOI: $10.16965 /$ ijpr.2019.108

International Journal of Physiotherapy and Research

ISSN (E) 2321-1822 | ISSN (P) 2321-8975

https://www.ijmhr.org/ijpr.html

DOI-Prefix: https://dx.doi.org/10.16965/ijpr

\section{Article Information}

Received: 24 Jan 2019

Peer Review: 24 Jan 2019

Revised: None
Accepted: 07 Mar 2019

Published (O): 11 Apr 2019

Published (P): 11 Apr 2019

\section{INTRODUCTION}

An infarction in the Middle cerebral artery territory is the most common site of cerebral ischemia [1]. The functional consequences of the primary neurologic deficits often predispose the stroke survivor to a sedentary lifestyle, which further limits the individual's activities of daily living (ADLs) and reduces cardiovascular reserves [2]. Of this approximately $90 \%$ of these suffer from persisting motor deficits leading to 
disability and handicap, namely dependence in their daily activities, impaired arm and hand function and impaired walking ability [3]. This makes the person to be bed ridden. There are many complications arise because of prolonged bed rest, which includes deep vein thrombosis, bed sores, lung secretions, pneumonia [4]. Thus it is very important to retain their bed mobility skills such as pelvic bridging, scooting, rolling to either side, rolling to side lying, side lying to sitting and sitting to supine lying thus preventing bed rest complications [5]. Day to day activities includes various functional tasks and activities which begin with bed mobility, one of the prime requisite for all other activities and task, enabling the individual to be functionally independent [6]. The need for innovative rehabilitation is clear because few wellresearched and effective therapies are available to individuals after stroke [7]. Of this motor learning emphasizes learning new strategies for sensing as well as moving. It involves a complex of perception, cognition, and action process. Retraining of bed mobility skills is very important to gain a better outcome in the later phases of rehabilitation and also to avoid abnormal and deviated pattern of movements and to improve the basic mobility skills $[6,8]$.

In retraining the bed mobility skills it is therefore important to remember there is no single correct strategy to be learned by the patient. So the goal when retraining bed mobility skills is to help him or her to develop sensory and motor strategies that are effective enough to meet the task requirements, though there is persisting impairments [6]. Based on the theoretical principles and concepts of motor learning there are numerous practice methods to retrain motor skills. Motor learning is enhanced by these practices. Higher practice sessions lead to greater learning. This correlates with the intensity of training [9]. Recent research had quoted that high intensity training had a very good mobility outcome even in acute stroke without any complications [10]. But the level of fatigue should also be considered and how the rest period is being scheduled. To answer this many research has been carried out with massed and distributed form of practice [6].

Massed and distributed practices are one of the most commonly used methods in post stroke rehabilitation. The main difference in these two practice method is such that in massed practice the practice time is equal to or more than the rest time whereas in distributed practice the practice time is less than the rest time. Numerous studies had been conducted to find out the effect of massed and distributed practice in normal individuals. The results showed that, for discrete tasks massed practice is suitable and for continuous tasks distributed practice is effective [6].

Need for the study: In a study by Laura Adomaitis Vearrier, Jeanne Langan, Anne Shumway-Cook, Marjorie Woollacott (2004), Intensive massed practice of standard physical therapy produced significant results in balance retraining with patients post-stroke. Their finding supported the need to offer additional practice to maximize the efficacy of physical therapy sessions [11]. Christian Dettmers et al (2004) concluded that Distributed CIMT is a promising intervention for improving motor function and QOL in patients with chronic stroke [12]. Many controversies exist such that it's not only the type of practice that makes a difference in performance of a task but also the nature of task. The research results are also not clear in particular for discrete tasks. Much of these studies were on activity based tasks and minimal or no studies were done on functional mobility [6]. There is still a lack of evidence that which practice method should be incorporated to effectively retrain basic mobility skills in patients immediately following stroke and there is no study that compared massed versus distributed practice to retrain basic mobility skills among post stroke patients. Hence the need of this study is to find out which practice method is effective in improving basic mobility skills among post stroke patients.

Objectives: To compare the effect of massed practice and distributed practice on basic mobility skills among post stroke patients.

\section{MATERIALS AND METHODS}

This study was a pre and post-test study with two comparison treatments. The study was conducted in Physiotherapy department at Kovai Medical Centre \& Hospitals 
Fig. 1 Illustrates the treatment protocol.

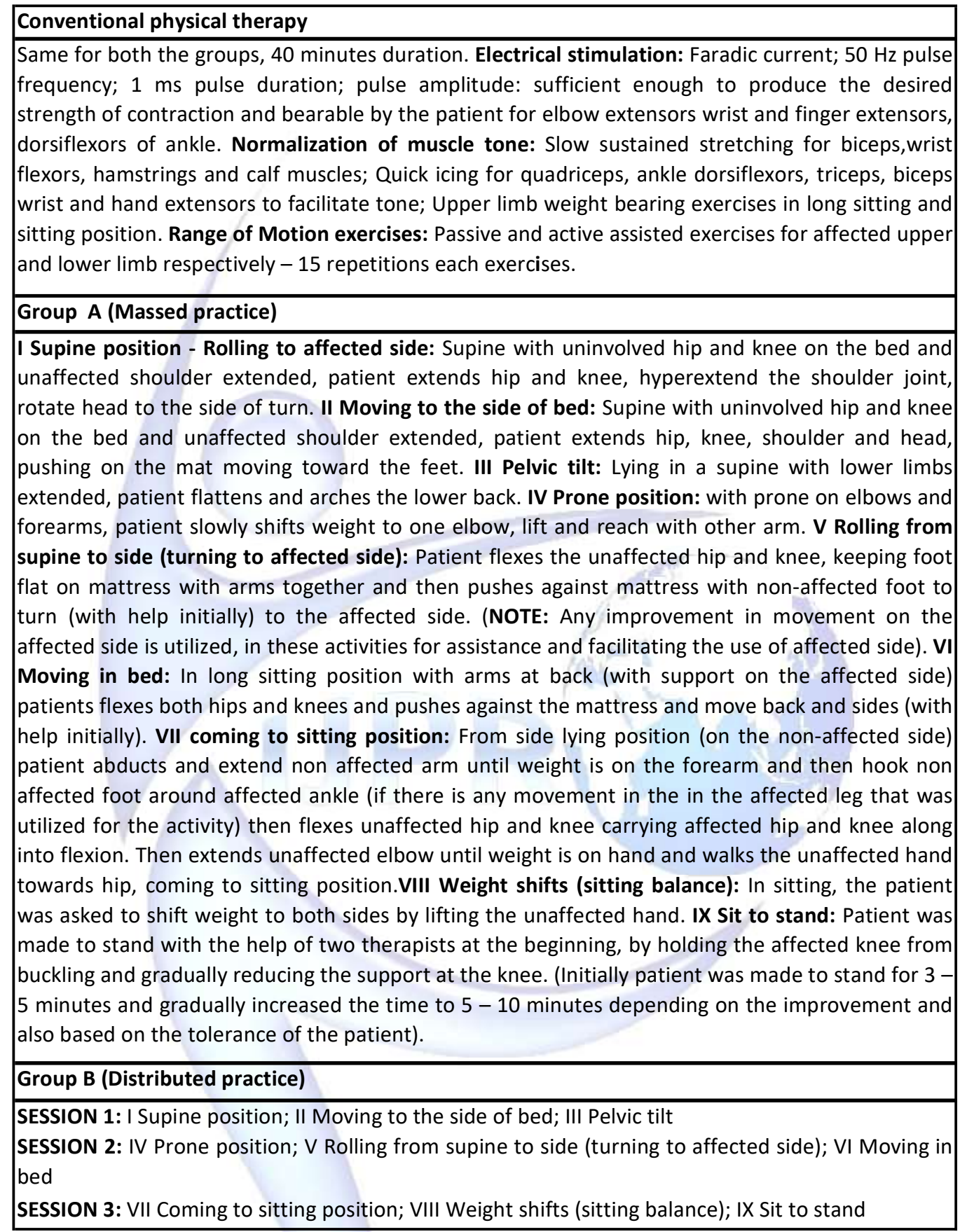

Participants: A total of 20 post stroke patients who met the inclusion criteria were randomly assigned in to two experimental groups. Group $A-10$ patients and group $B-10$ patients.

Inclusive criteria for the study includes first episode of left middle cerebral artery ischemic stroke patients with age between 40 to 55 years. 5 days from stroke onset with Brunnstrom's Stroke Recovery stage - 2 (recovery begins, the basic limb synergies or some of their components may appear as associated reactions, or minimal voluntary movement responses may be present) and able to follow simple verbal commands.
Exclusive criteria for the study includes haemorrhagic stroke, Anterior cerebral artery stroke, cerbellar and brainstem lesions, cognitive and perceptual disorders, other orthopedic, neurological problems and movement disorders, severe cardiac problems (recent myocardial infarction, post CABG patients $\mathrm{CHF}$, uncontrolled hypertension $\{B P>190 / 110 \mathrm{mmHg}$, arrhythmias), visual and auditory impairments (not correctable).

Procedure: A written consent was obtained from the patients who fulfilled the inclusion and exclusion criteria and randomly assigned to two groups. Group A received bed mobility training 
in massed practice method and conventional physical therapy. Group B received bed mobility training in distributed practice method and conventional physical therapy. An outcome assessor who was blinded to the group allocation took the outcome measurements using Stroke Rehabilitation Assessment of Movement (STREAM) scale. Initial assessment was taken on the first day before therapy. Intervention was given to each group separately for 7 days. Post assessment was taken after the 7 days of physiotherapy treatment using the same outcome measures. Comparison of pretest and posttest values within the group and between the groups was done finally.

Intervention: Both the groups received conventional therapy of 40 minutes and experimental intervention of 60 minutes for 7 days. Group A patients received bed mobility training in massed practice method -60 minutes session with rest period never exceeding the exercise period. Group B patients received bed mobility training in distributed practice method $-20 \mathrm{~min}$ utes per session with rest period exceeding the exercise period, 3 sessions per day. All exercises were done with assistance initially and gradually reducing the assistance as the patient improves. Exercises that were performed by both the groups are given in Figure 1.

Outcome measures: Functional mobility before and after intervention was assessed using Bed mobility items of Stroke Rehabilitation and Assessment of Movement (STREAM) scale. Test-retest and inter observer reliability for the STREAM scale mobility component was 0.98 and 0.99 respectively.

Data analysis: The data were analyzed using SPSS 17.0. Paired ' $t$ ' test was used to find the difference within the group between pre and post intervention scores in the outcome measures. Independent ' $\mathrm{t}$ ' test was used to find the difference between the groups in the outcome measure. The statistical significance for this study was set as $p<0.05$.

\section{RESULTS}

The aim of this study is to find out which practice method (massed practice and distributed practice) is effective in improving basic mobility skills among post stroke patients. As shown in Table 1, all participants in group $A$ and group $B$, showed significant improvement in basic mobility item of STREAM scale scores with a mean difference of 11.2 and 15.9 , respectively. The calculated ' $\mathrm{t}$ ' value for using the paired ' $\mathrm{t}$ ' test for group A and group B were 27.03 and 51.36 respectively which was greater than the table ' $\mathrm{t}$ ' value of $2.2621 ; \mathrm{P}<0.05$. This shows that there is a significant improvement in basic mobility skills in both the groups.

Table 1: Mean, mean difference and Paired ' $t$ ' test values of basic mobility item of STREAM scale of groups A\&B.

\begin{tabular}{|c|c|c|c|c|}
\hline Groups & Means & $\begin{array}{c}\text { Mean } \\
\text { difference }\end{array}$ & ' $t$ ' value & 'p' value \\
\hline \multicolumn{5}{|c|}{ Group A } \\
\hline Pre test & 4.4 & \multirow{2}{*}{11.2} & \multirow{2}{*}{27.03} & \multirow{2}{*}{$p<0.05$} \\
\hline Post test & 15.6 & & & \\
\hline \multicolumn{5}{|c|}{ Group B } \\
\hline Pre test & 4.6 & \multirow{2}{*}{15.9} & \multirow{2}{*}{51.36} & \multirow{2}{*}{$p<0.05$} \\
\hline Post test & 20.5 & & & \\
\hline
\end{tabular}

Graph 1: Pre test and post test mean values of basic mobility item of STREAM scale for group - A (Massed practice)

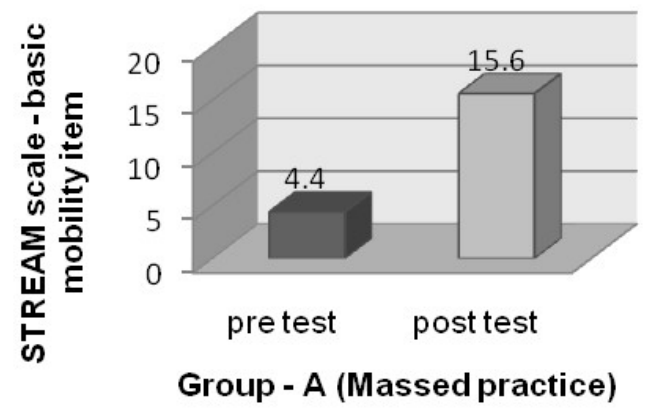

Graph 2: Pre test and post test mean values of basic mobility item of STREAM scale for group - B (Distributed practice)

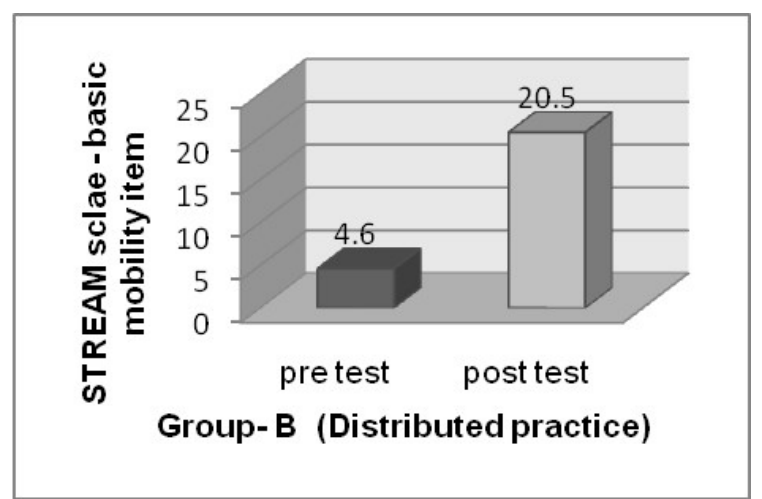

As shown in Table 2, when comparing the groups using independent ' $\mathrm{t}$ ' test, the basic mobility item of STREAM scale scores showed mean difference of 4.9 and the ' $t$ ' value of 9.17. This results shows that there is a statistically significant improvement in group $B$ which 
underwent bed mobility training using distributed practice method.

Table 2: Mean, mean difference and Independent " $\mathrm{t}$ " Test values of basic mobility item of STREAM scale of groups $\mathrm{A} \& \mathrm{~B}$.

\begin{tabular}{|c|c|c|c|}
\hline Outcome measure & $\begin{array}{c}\text { Mean } \\
\text { difference }\end{array}$ & ' $t$ ' value & ' $\mathbf{p}$ ' value \\
\hline $\begin{array}{c}\text { Basic mobility item of } \\
\text { STREAM scale }\end{array}$ & 4.9 & 9.7 & $p<0.05$ \\
\hline
\end{tabular}

Graph 3: Post test mean values of basic mobility item of STREAM scale for groups - A \& B. (Massed \& Distributed practice)

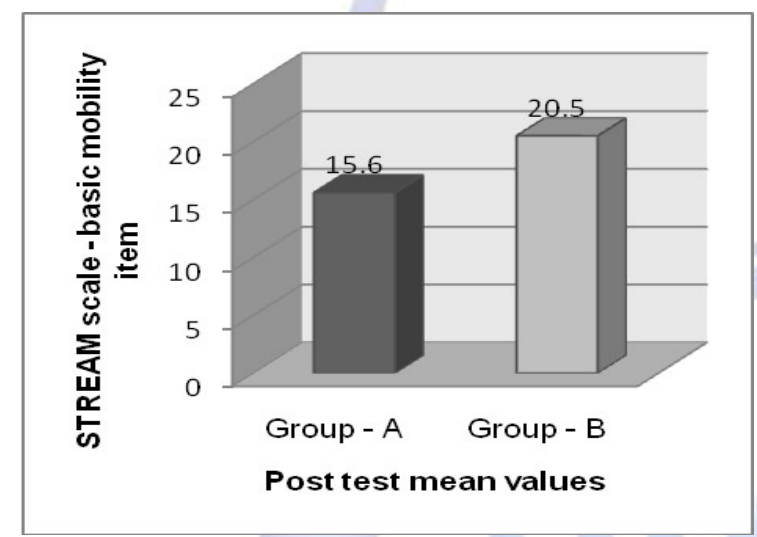

\section{DISCUSSION}

The findings states that both the groups showed improvements in mobility skills, which can be explained by cortical reorganisation occurring at the early stage after stroke; enhancing neuro plasticity and learning with early active training in both groups[9, 13]. But it should also be remembered that learning is also affected by the type of task $[8,6]$. The entire tasks in the study were discrete activities. It's well known that for continuous task distributed practice is effective and for discrete task massed practice is effective, and also the intensive the task the better the outcome. Schmidt \& Lee (2005) stated that research results are also not clear for the discrete tasks and tend to depend upon the nature of the task [6].

According to the statement above massed practice group should have better functional outcome but the results is contradicting since distributed practice group showed a greater improvement in both outcome measure. The possible reason for better improvement in distributed practice group may be they developed less fatigue during rehabilitation because of the rest period. This correlates with the study findings by Steven R. Murray et al., in which he concluded that because of the fatigue developed during the massed practice in acute stages during rehabilitation, distributed practice is effective and in later stages massed practice can be effectively employed [14].

This could be explained by the concept of fatigue both peripheral (muscle) and central (neural) which leads to reactive inhibition in the massed group compared to that of distributed practice group. Fatigue developed during the treatment session had decremented the performance of massed practice group. During the treatment session it was noted that the performance in the ability to perform sit to stand transfers, standing, and stepping activity in the massed practice group was reduced as they followed through rolling, bridging and weight shifting activities with little rest periods. Patient's cognitive learning ability would also have been affected because of this and they might have been psychologically less motivated on seeing their inability to tolerate the continuous therapy session. This might be the reason why they scored comparatively less in the standing item of the basic mobility item of STREAM scale. Both group showed only a little improvement from the baseline values for the stepping and walking items. This can be explained by the fact that improvement in functional task or activities with rehabilitation correlates with the nature and type of task practiced and also with the amount of training [15].

Both the Group - A (massed practice) and Group - B (distributed practice) had spent the same duration (one hour) in training but the intervention given to both groups had not included activities like stepping and walking. So there is only a minimal generalisation from the activities given in the intervention to the stepping and walking activities. But what made the distributed practice group to show better learning of skills can be explained by the 'principle of expanding rehearsal' as suggested by Schmitt \& Schmitt (1995). According to this principle longer the interval the better the practice items can be recalled [16]. So participants in the distributed practice group had two advantages when compared with the massed practice group, (i) rest period had prevented them from developing fatigue so poor performance is prevented 
and (ii) sufficient rest period had allowed them to recall the task trained. The result of this study was similar to the results by Conti GE et. al., who studied the changes in hemiplegic grasp following distributed repetitive intervention and showed that distributed practice was sufficient to effect change in grasp force and quality of handwriting [17]. While there is not any abundance of information regarding the optimal number of practice and length of practice sessions, the available evidence points to the benefit the distributed practice. Result of this study states that relearning of motor skills occurs in both massed and distributed practice. Acquisitions of basic mobility skills were similar but performance is better in distributed practice when compared to that of massed practice. Spacing effect can be successfully applied to a functional task such as bed mobility.

\section{Limitations of the study}

1. Sample size was small.

2. Short study duration.

3. Study was done only in left middle cerebral artery ischemic stroke population.

4. Follow up was not done. Retention of the skills was not assessed; only acquisition and performance of motor skills were measured.

\section{CONCLUSION}

Motor learning principles and concepts are now been extensively applied and studied in the researches. The aim of this study was to compare the effect of massed practice and distributed practice on retraining basic mobility skills among post stroke patients. The results of the study showed that bed mobility skills improved in both massed and distributed practice method. But distributed practice group had significant improvement than massed practice group in retraining basic mobility skills in post stroke patients in the acute stage. Hence distributed practice can be applied to acute stroke patients in their rehabilitation process to retrain basic mobility skills and promote better motor recovery.

\section{Conflicts of interest: None}

\section{REFERENCES}

[1]. Adams RD, Victor M, Ropper AH. Cerebrovascular Disease. In: Adams RD, Victor M, Ropper $A H$, editors. Principles of Neurology. New York: McGrawHill, Health Professions Division, 1997;777-873.

[2]. Da Cunha et al., Gait Outcomes After Acute Stroke Rehabilitation With Supported Treadmill Ambulation Training: A Randomized Controlled Pilot Study, Arch Phys Med Rehabil 2002;83:1258-65.

[3]. Stefan Hesse Treadmill training with partial body weight support after stroke: A review NeuroRehabilitation 2007;22:1-11.

[4]. Carr JH, Shepherd RB, editors. Movement Science: Foundations for Physical Therapy in Rehabilitation. Rockville, MD: Aspen; 1987.

[5]. National Institute of Neurologic Disorders and Stroke.

[6]. Anne Shumway-Cook, Marjorie Woollacott. Motor Control Theory and Applications. $3^{\text {rd }}$ Edition. Lippincot Williams and Wilkins.

[7]. Stacy L. Fritz et al., Active Finger Extension Predicts Outcomes After Constraint-Induced Movement Therapy for Individuals With Hemiparesis After Stroke. Stroke 2005; 36:1172-1177.

[8]. Janet H. Carr, Roberta B. Shepherd. A Motor Relearning Programme for stroke, $2^{\text {nd }}$ edition, ButterworthHeinemann oxford publications.

[9]. Gert Kwakkel et al., Functional Recovery After Stroke: A Review of Current Developments in Stroke Rehabilitation Research. Reviews on Recent Clinical Trials, $2006 ; 1: 75-80$.

[10]. Suzanne S Kuys et al., Higher-intensity treadmill walking during rehabilitation after stroke in feasible and not detrimental to walking pattern or quality: a pilot randomized trial. Clinical Rehabilitation 2011;25:316-326.

[11]. Laura Adomaitis Vearrier, Jeanne Langan, Anne Shumway-Cook, Marjorie Woollacott. An intensive massed practice approach to retraining balance post-stroke. Published online 25 October 2004.

[12]. Dettmers C, Teske U, Hamzei F, Uswatte G, Taub E, Weiller C. Distributed form of constraint-induced movement therapy improves functional outcome and quality of life after stroke. Third World Congress of Neurological Rehabilitation, April 2002, Venice.

[13]. Nick et al., The timing of initiation of rehabilitation after stroke, Arch Phys Med Rehabil 2004.

[14]. Steven R. Murray et al., Massed versus Distributed Practice: Which is Better? - Review, CAHPERD Journal, 2003;28(1).

[15]. John W. Krakauer, Motor learning: its relevance to stroke recovery and neurorehabilitation. Current Opinion in Neurology 2006;19:84-90.

[16]. Yousif Alshumaimeri, 14-12-01 Massed versus distributed, a review 14- $12-10$.

[17]. Conti GE, Schepens SL. Changes in hemiplegic grasp following distributed repetitive intervention: a case series.Occup Ther Int. 2009;16(3-4):204-17.

How to cite this article: Parthiban Alagappan. EFFECT OF MASSED PRACTICE VERSUS DISTRIBUTED PRACTICE ON BASIC MOBILITY SKILLS AMONG POST STROKE PATIENTS. Int J Physiother Res 2019;7(2):3028-3033. DOI: 10.16965/ ijpr.2019.108 